\title{
Proteomic Analysis of Soybean Root Hairs After Infection by Bradyrhizobium japonicum
}

\author{
Jinrong Wan, ${ }^{1,4}$ Michael Torres, ${ }^{2}$ Ashwin Ganapathy, ${ }^{3}$ Jay Thelen, ${ }^{4}$ Beverly B. DaGue, ${ }^{5}$ Brian Mooney, \\ Dong $\mathrm{Xu}^{3}$ and Gary Stacey ${ }^{1,4}$ \\ ${ }^{1}$ National Center for Soybean Biotechnology, Department of Plant Microbiology and Pathology, University of Missouri, \\ Columbia, MO 65211, U.S.A.; ${ }^{2}$ Department of Biology, Maryville College, Maryville, TN 37804, U.S.A.; ${ }^{3}$ Department of \\ Computer Science, University of Missouri, Columbia, MO 65211, U.S.A.; ${ }^{4}$ Department of Biochemistry, University of \\ Missouri, Columbia, MO 65211, U.S.A.; ${ }^{5}$ Proteomics Center, University of Missouri, Columbia, MO 65211, U.S.A.
}

Submitted 12 October 2004. Accepted 6 January 2005.

\begin{abstract}
Infection of soybean root hairs by Bradyrhizobium japonicum is the first of several complex events leading to nodulation. In the current proteomic study, soybean root hairs after inoculation with $B$. japonicum were separated from roots. Total proteins were analyzed by two-dimensional (2-D) polyacrylamide gel electrophoresis. In one experiment, 96 protein spots were analyzed by matrix-assisted laser desorption ionization time-of-flight (MALDI-TOF) mass spectrometry (MS) to compare protein profiles between uninoculated roots and root hairs. Another 37 spots, derived from inoculated root hairs over different timepoints, were also analyzed by tandem MS (MS/MS). As expected, some proteins were differentially expressed in root hairs compared with roots (e.g., a chitinase and phosphoenolpyruvate carboxylase). Out of 37 spots analyzed by MS/MS, 27 candidate proteins were identified by database comparisons. These included several proteins known to respond to rhizobial inoculation (e.g., peroxidase and phenylalanine-ammonia lyase). However, novel proteins were also identified (e.g., phospholipase $D$ and phosphoglucomutase). This research establishes an excellent system for the study of root-hair infection by rhizobia and, in a more general sense, the functional genomics of a single, plant cell type. The results obtained also indicate that proteomic studies with soybean, lacking a complete genome sequence, are practical.
\end{abstract}

Additional keywords: legume, rhizobium, symbiosis.

Root hairs are specialized projections from modified epidermal cells of the root that are thought to increase the effective surface area for nutrient and water uptake, enlarge the volume of exploited soil, and aid in anchoring the plant to the soil (Bibilova and Gilroy 2003). In legumes, root hairs are also the preferred site of infection by rhizobia (species of the genera Azorhizobium, Bradyrhizobium, Mesorhizobium, Sinorhizobium, and Rhizobium). The interaction between rhizobia and leguminous plants is complex, leading to the formation of a special organ (i.e., nodule) on the root, which the rhizobia colonize and in which they subsequently reduce atmospheric nitrogen into ammonia for plant use (Cullimore et al. 2001).

Rhizobial infection of root hairs exhibits fascinating cell biology. Briefly, the induction of the rhizobial nodulation genes by

Corresponding author: Gary Stacey; E-mail: staceyg@missouri.edu

Current address of M. Torres: Warren Wilson College, Asheville, NC, U.S.A. flavonoid compounds released by leguminous plants leads to the synthesis of the lipo-chitin nodulation factors, which can deform root hairs. The rhizobia are attracted and entrapped by the deformed root hairs. They enter the root hair via endocytosis and are enclosed in a new subcellular structure called the infection thread, which is formed from the invagination of the root-hair cell plasma membrane. Upon exiting the root-hair cell, the infection thread extends into the dividing cortical cells, which are forced to reenter cell division before the infection thread reaches the cortical region. The cortical cells divide to form the nodule primordium and the nodule meristem. Finally, rhizobia are endocytosed from the infection thread into infected plant cells within the vacuole-like symbiosome, in which the bacteria differentiate into bacteroids. The nodule provides an environment of low oxygen and available nutrients suitable for nitrogen fixation (Lum and Hirsch 2003; Stougaard 2000).

During nodule formation, many host genes are activated by the legume-Rhizobium interaction, such as nodulin genes ENOD12, ENOD11, ENOD40, extensins, glycine-rich proteins (GRPs), and leghemoglobin (Cohn et al. 1998; Geurts and Bisseling 2002; Legocki and Verma 1980; Oldroyd 2001; Schultze and Kondorosi 1998). Most previous studies focused on gene regulation in roots as a general tissue. However, root hairs are the extensions of root epidermal cells in the elongation zone and are the primary sites for rhizobial infection. They are morphologically and probably also biochemically different from the remaining epidermal cells and roots. Therefore, their response to the rhizobial infection may also be different from that of roots in terms of protein species, induction level, and kinetics.

Proteomics has become an important tool in the study of plant biology (Heazlewood and Millar 2003; Kersten et al. 2002; Rossignol 2001; Thiellement et al. 1999; van Wijk 2001). In the last decade, proteomics has succeeded in identifying approximately 400 proteins associated with the development and functioning of both mycorrhizal and rhizobial symbioses (Bestel-Corre et al. 2004; Rolfe et al. 2003; Trevaskis et al. 2002). Other previous studies have focused on leguminous seeds (Mooney and Thelen 2004), roots (Bestel-Corre et al. 2002; Morris and Djordjevic 2001; Natera et al. 2000), nodules (Natera et al. 2000), symbiosome membranes of nodules (Panter et al. 2000; Saalbach et al. 2002; Wienkoop and Saalbach 2003), symbiosome space (Saalbach et al. 2002), as well as bacteroids (Natera et al. 2000) and mitochondria in soybean nodules (Hoa et al. 2004). In addition, proteome reference maps have been developed for leaves, stems, flowers, seed pods, cell suspension 
cultures (Watson et al. 2003), and roots (Mathesius et al. 2001; Watson et al. 2003) of the model legume Medicago truncatula.

Modern functional genomic tools now allow a genomic view of gene regulation but require an extensive knowledge of the genome sequence. In the case of soybean, a genomic sequence is not available but an extensive expressed sequence tag (EST) database is available on the Soybean EST Project website (334,668 EST sequences as of Aug. 6, 2004). The current study focused on whether this information would be sufficient to conduct detailed proteomic studies on the initial root hair interaction between soybean and its compatible symbiont $B$. japonicum. Examining a single-cell type, which may be highly specialized, appeared to be a critical test of this technology. The elegance of this study is that a sufficient amount of singlecell root hairs can be obtained relatively readily from soybean, due to its larger size. Similar efforts would be very laborious in smaller legume species (e.g., M. truncatula) that are now the focus of extensive genetic analysis (Cook 1999; Young et al. 2003). Soybean root hairs (ranging from 0.5 to $1 \mathrm{~g}$ of fresh weight), treated with either B. japonicum or water, were isolated for proteomic analysis. The protein profiles of root hairs and soybean roots (stripped of root hairs) were first compared to see how roots and root hairs are different at the protein level. Proteins regulated by B. japonicum infection were identified by comparing protein profiles of control root hairs treated with water or a B. japonicum $\mathrm{NodC}^{-}$mutant (unable to make Nod factor) with profiles for wild-type $B$. japonicuminfected root hairs. As expected, a number of proteins appeared to be regulated by the bacterium. Some of these proteins were previously shown to be involved in symbiotic interactions, e.g., lipoxygenase and phenylalanine-ammonia lyase, and some are new proteins not previously shown to be associated with this process, e.g., phospholipase D and a phosphoglucomutase. The results of this study demonstrate that current soybean genomic resources are sufficient to allow protein identification by matrixassisted laser desorption ionization time-of-flight (MALDITOF) and mass spectrometry (MS) analysis and that soybean single-cell root hairs are a good tissue for proteomic analysis of the early events of soybean-Rhizobium interaction.

\section{RESULTS}

\section{Isolation of soybean root hairs.}

To obtain sufficient pure soybean root hairs for the current proteomic study, root hairs were physically sheared off soybean roots (Fig. 1A and B) and further separated from the remaining roots (i.e., stripped roots) by filtering. The stripped roots (Fig. $1 \mathrm{C}$ and D) and separated root hairs (Fig. 1E) were examined microscopically for quality control purposes. As shown in Figure $1 \mathrm{C}$ and $\mathrm{D}$, no apparent root hairs remained on the root after shearing, although remnants of the sheared hairs do remain. Root hairs collected through stirring and filtering were also examined. They appeared to be tube-like, with a diameter of 15 to $25 \mu \mathrm{m}$, and most of them were broken due to physical stirring (Fig. 1E). Roughly, 4,000 soybean seedlings grown in 50 large glass petri dishes produced $1 \mathrm{~g}$ of root hairs (fresh weight), from which approximately $1.5 \mathrm{mg}$ of total protein could be isolated for proteomic analysis.

\section{Comparison of soybean roots and root-hair protein profiles.}

As mentioned above, root hairs are the extensions of root epidermal cells and are morphologically different from the remaining root cells. Therefore, they may show differences in their protein profile relative to stripped roots. In order to compare these two, the root hairs of uninoculated soybean seedlings were isolated and their protein profiles were compared

with their respective "stripped roots." In general, the two-dimensional (2-D) images from root hairs and stripped roots looked very similar (Fig. 1A). After image analysis, 96 spots were excised for MALDI-TOF MS analysis (Fig. 2B). The majority of the spots selected appeared to be differentially expressed between stripped roots and root hairs based on cursory image analysis, but spots that did not appear to be differentially expressed were also included. After the Student's $t$ test, approximately half of the spots showed a significant difference $(p<$ 0.05 ) between root hairs and stripped roots. Among these, 12 were unique to root hairs, one was absent in root hairs, 24 were up-regulated in root hairs, and nine were down-regulated in root hairs. After interrogating the Soybean UniGene database with tryptic peptide masses from each protein spot, at a mass tolerance of $150 \mathrm{ppm}$ (parts per million), approximately $24 \%$ of the spots $(=23)$ returned candidate protein assignments (Table 1). As a practical cut-off value, a minimum of four peptide matches and a molecular weight search (MOWSE) score $>200$ were employed, except for one hit (spot 15), which has a MOWSE score $<200$ but a very good match between experimental and theoretical MW/pI (molecular weight/isoelectric point) values. To exclude possible false positives, the experimental MW and pI values must be similar to their corresponding theoretical values (generally with a $<20 \%$ difference). However, this may also exclude some potential candidates, due to the difference between experimental and theoretical MW/pI values as a result of posttranslational modifications. Among these 23 hits, 14 were also confirmed by IntelliCal at a mass
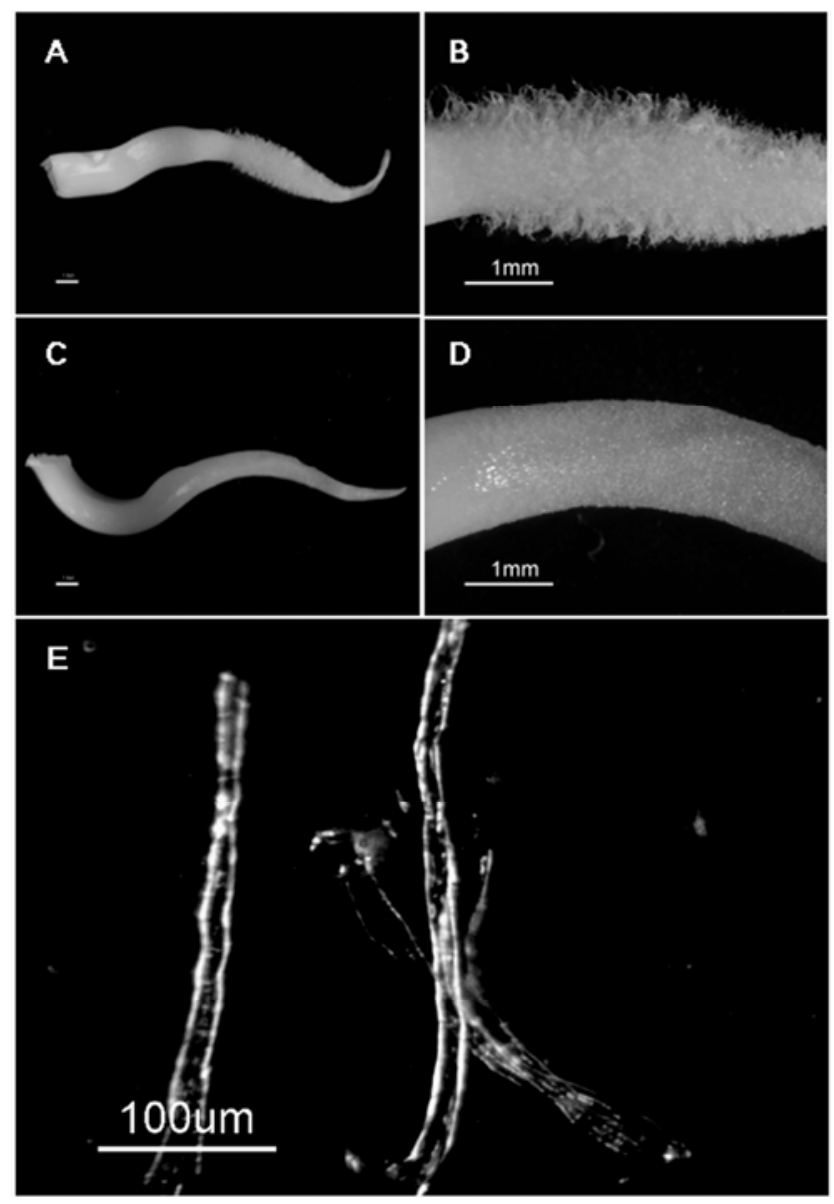

Fig. 1. Soybean root and root hairs. A and B, A soybean root before the stripping of root hairs. $\mathbf{C}$ and $\mathbf{D}$, A soybean root after the stripping of root hairs ("stripped root"). E, The microscopic image of isolated root hairs. In $\mathrm{A}, \mathrm{B}, \mathrm{C}$, and $\mathrm{D}$, the bar corresponds to $1 \mathrm{~mm}$. In E, the bar corresponds to $100 \mu \mathrm{m}$. 
tolerance of $15 \mathrm{ppm}$ (discussed below). Of these 23 spots or proteins (Table 1), two appeared to be present only (unique) in root hairs (chitinase class I [spot 54] and a stress-induced gene H4 [spot 94]). Twelve spots or proteins were more abundant in root hairs than in roots. For example, levels of ascorbate peroxidase 2 (APx2, spot 69), CDPK:calmodulin-like domain protein kinase isoenzyme $\beta$ (spot 15), phosphoenolpyruvate (PEP) carboxylase (spot 3), and $\beta$ 7-tubulin (spot 14) were elevated in root hairs. On the other hand, four spots or proteins

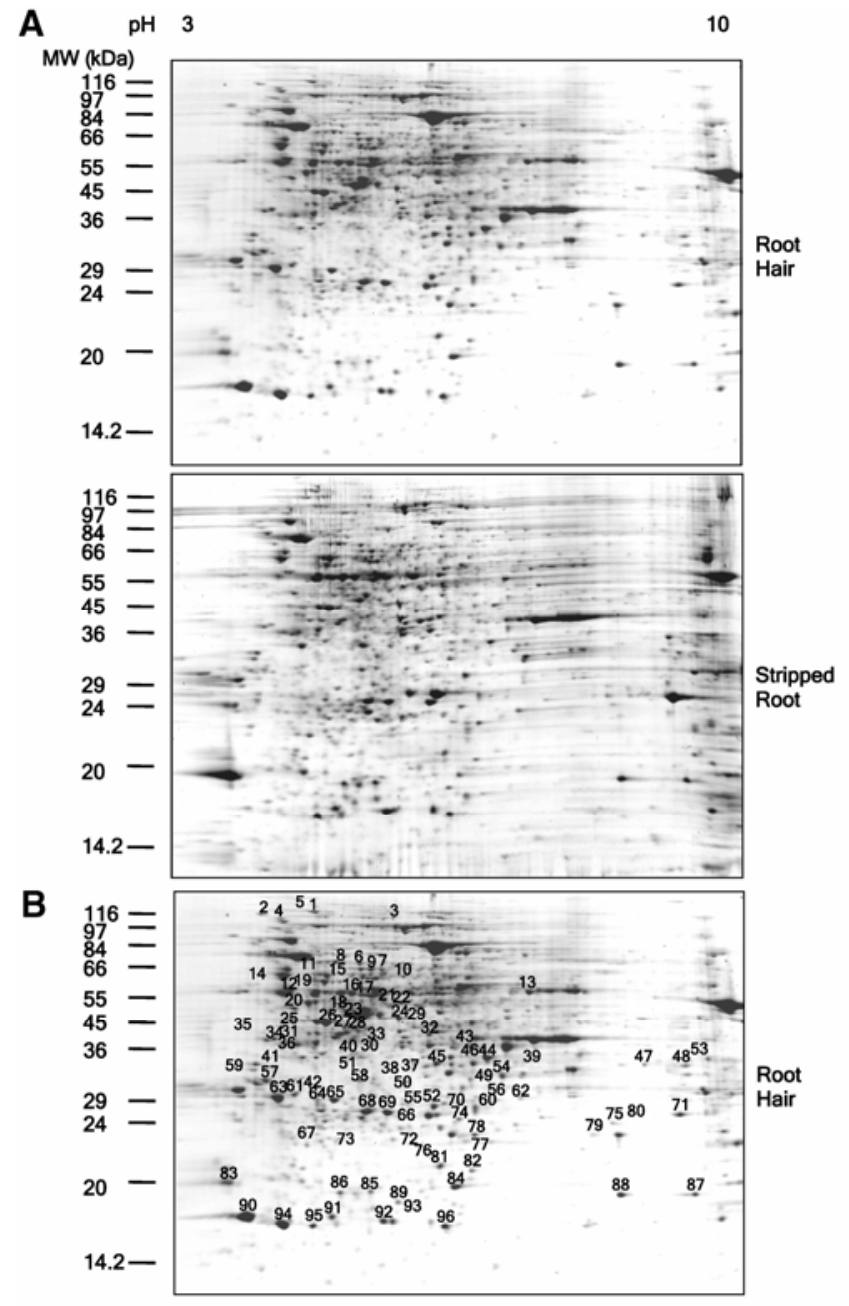

C

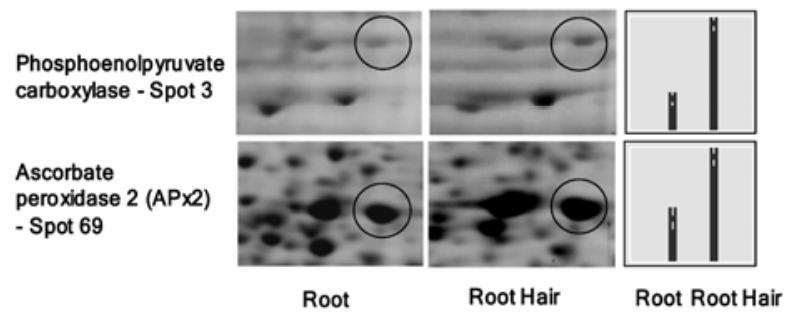

Fig. 2. Comparisons of soybean stripped root and root-hair two-dimensional (2-D) protein gel images. A, Images of whole $2-\mathrm{D}$ gels. The $\mathrm{pH}$ range (3 to 10) of the immobilized $\mathrm{pH}$ gradient strips is shown above the gel images, and the positions of protein molecular weight markers, MW (kDa), are indicated to the left of the gel images. B, The spots selected for matrixassisted laser desorption ionization time-of-flight mass spectrometry analysis were numbered (1 to 96) on the root hair gel image either right above the spots or as shown by an arrow in a few cases. C, Highlights of Spot 3 , phosphoenolpyruvate carboxylase, and spot 69, ascorbate peroxidase 2 (APx2). The bar graphs show average intensities for the highlighted spot, together with standard deviations. Three biological replicates were included for both root hair and stripped root samples. were more abundant in stripped roots than in root hairs, e.g., glutathione- $S$-transferase 8 (spot 73). Several (four) spots or proteins showed equivalent expression between stripped roots and root hairs. Examples include a NADP-specific isocitrate dehydrogenase (idh1, spot 24) (Table 1).

As an example, Figure $2 \mathrm{C}$ highlights two regions of the gels shown in Figure 2A. These regions demonstrated elevated expression of PEP carboxylase and ascorbate peroxidase in root hairs (Fig. 2C, bar graph).

\section{Identification of soybean root-hair proteins affected by $B$. japonicum infection.}

2-D protein profiles of root hairs treated with B. japonicum or water (as a control) were compared $0,3,6$, and 12 hours posttreatment, to identify root-hair proteins responsive to $B$. japonicum infection. Analysis of these 2-D gel images identified 26 spots that appeared to be differentially expressed between the two treatments. These proteins were analyzed by nanospray quadrupole $(\mathrm{Qq}) \mathrm{TOF}$ tandem MS (MS/MS) for protein identification. After querying the MS/MS data against the NCBInr protein database using Mascot, 17 spots were identified with one or a few potential candidate proteins (Table 2). Only the top candidate protein for each spot is listed in Table 2. In total, these 17 spots represent 16 proteins, due to the fact that one individual pair of spots had the same protein identification (i.e., spots 4 and 6, endopeptidase Clp ATP-binding chain), suggesting possible posttranslational modification of the protein. Among the proteins identified were some previously known to respond to inoculation, e.g., lipoxygenase, phenylalanine-ammonia lyase, and L-ascorbate peroxidase 1 . However, additional proteins were also found to respond to B. japonicum treatment. These included endopeptidase Clp ATP-binding chain, phospholipase D, vesicular fusion protein, phosphoglucomutase, peptidylprolyl isomerase, a putative heat shock 70-kDa protein mitochondrial precursor, 2,3-bisphosphoglycerate-independent phosphoglycerate mutase, chaperonin, mitochondrial processing peptidase, isocitrate dehydrogenase, cinnamyl-alcohol dehydrogenase, and a protein-related disease resistance response. As an example, Figure 3A shows highlighted regions of representative protein gels revealing elevated expression of phospholipase D, phosphoglucomutase, alanyl t-RNA synthetase, and lectin precursor during the time course of the experiment.

A similar experiment compared protein profiles between root hairs inoculated with wild-type $B$. japonicum and a $B$. japonicum $\mathrm{NodC}^{-}$mutant incapable of synthesizing the lipochitin nodulation signal required to initiate the nodulation process (Loh and Stacey 2001). Since the above previous experiments showed that most root-hair proteins had $\mathrm{pI}$ values in the range of $\mathrm{pH} 4$ to $\mathrm{pH} \mathrm{7,} \mathrm{immobilized} \mathrm{pH}$ gradient (IPG) strips with this narrower $\mathrm{pH}$ range were used to improve resolution (Westbrook et al. 2001). In addition, the time course was extended to $18 \mathrm{~h}$ posttreatment in an attempt to identify proteins that might respond later to bacterial infection. Comparison between the gel images revealed 11 spots that appeared to require Nod factor production by B. japonicum. After trypsin digestion, these spots were analyzed using MALDI-TOF MS or MS/MS (Table 3). Peptides from four of the spots were matched by MASCOT searches of the viridiplantae database with statistically significant scores $(P<0.05)$ (top four are listed in Table 3) and were not further analyzed by MS/MS. Once again some proteins known to respond to inoculation were identified, such as lipoxygenase, phenylalanine ammonia lyase 1 , lectin precursor, a protein similar to early nodulin 18 (Vicia faba, NCBInr 11602751), and chalcone-flavonone isomerase A. Note that both lipoxygenase and phenylalanineammonia lyase 1 were among the proteins identified in our previous experiment. Several new proteins were identified that 
required NodC function for expression. These included alanyl t-RNA synthetase, mitochondrial precursor, metacaspase 1, trypsin inhibitor, a probable enoyl-(acyl-carrier-protein) reductase (NADH2), and a glycine-rich RNA-binding protein similar to porcine 40S ribosomal protein S12 (Swiss-prot P46405). Two examples are shown in Figure $3 \mathrm{~B}$ to illustrate their relative expression levels in comparison to the corresponding control at each timepoint (Fig. 3B).

\section{DISCUSSION}

Root hairs-an excellent single-cell tissue for the proteomic study of soybean-Rhizobium symbiotic interactions.

The purpose of this study was to investigate the practical application of proteomic tools to analyze $B$. japonicum infection of soybean root hairs. To the best of our knowledge, this is the first proteomic study on this important tissue. A unique aspect of the study was the ability to apply functional genomic methods to a single, plant cell type. One of the key features of the current study was that sufficient, pure root hairs could be collected from soybean roots for proteomic analyses. Similar studies on model legumes (e.g., L. japonicus or M. truncatula) would be extremely laborious given their small size.

\section{Root hair-specific proteins.}

Protein profiles of stripped roots and root hairs were very similar. This is not too surprising, since root hairs are the extension of root epidermal cells. However, a number of proteins or spots appeared to be differentially expressed between roots and root hairs (Table 1; Fig. 2). For example, two selected spots or proteins appeared to be specific to root hairs, and twelve proteins appeared to be more abundant in root hairs than in stripped roots. On the other hand, some spots or proteins were more abundant in stripped roots compared with root hairs. For example, chitinase class I (spot 54) and a stressinduced gene H4 (spot 94) appeared to be present only in root hairs; CDPK:calmodulin-like domain protein kinase isoenzyme $\beta$ (spots 15), phosphoenolpyruvate (PEP) carboxylase (spot 3), and ascorbate peroxidase 2 (spot 69) appeared more abundant in root hairs than in stripped roots; and glutathione $S$ transferase GST8 (spot 73) (AF243363) was more abundant in stripped roots than in root hairs (Table 1). Those proteins more abundant in root hairs may play specific roles in root-hair development or physiology. One interesting example is CDPK:calmodulin-like domain protein kinase isoenzyme beta (spots 15). This protein is $37 \%$ identical and $57 \%$ similar (at amino acid level) to a recently identified protein DMI3 from $M$. truncatula, which is required for bacterial and fungal symbioses in legumes but does not respond to inoculation (Ané et al. 2004; Lévy et al. 2004). Also of interest to the soybean symbiosis is the elevated expression of PEP carboxylase in root hairs, in which it could produce dicarboxylic acids, a preferred carbon source for rhizobial bacteroids (Rosendahl et al. 1990; Streeter 1995).

\section{Proteins that respond to $B$. japonicum inoculation.}

The current study, as expected, identified some proteins previously known or suggested to respond to rhizobial inocula-

Table 1. Proteins identified by matrix-assisted laser desorption ionization time-of-flight (MALDI-TOF) mass spectrometry (MS) in soybean roots and root hairs and their relative expression levels ${ }^{\mathrm{a}}$

\begin{tabular}{|c|c|c|c|c|c|c|c|c|c|c|}
\hline Spot $^{b}$ & vs. Roots & Top Hit & GenBank & MOWSE $^{c}$ & PMed & E-MW & E-pI & T-MW & T-pI & IntelliCal \\
\hline 54 & Unique & Chitinase class I & AF202731 & $1.32 \mathrm{E}+05$ & 7 & 34.4 & 7. & 34.3 & 7.4 & No \\
\hline 94 & Unique & Stress-induced gene H4 & AI460978 & $1.95 \mathrm{E}+03$ & 5 & 19.6 & 4.7 & 16.8 & 4.9 & Yes \\
\hline 3 & $3.2 \pm 0.4(0.011)$ & $\begin{array}{l}\text { Phosphoenolpyruvate (PEP) } \\
\text { carboxylase }\end{array}$ & D10717 & $3.41 \mathrm{E}+04$ & 12 & 105 & 6.0 & 111 & 6.1 & Yes \\
\hline 14 & $2.3 \pm 0.1(0.013)$ & $\beta-7$ tubulin & AI507834 & $1.79 \mathrm{E}+06$ & 15 & 56.9 & 4.6 & 50.1 & 4.7 & Yes \\
\hline 15 & $3.1 \pm 0.2(0.027)$ & $\begin{array}{l}\text { CDPK: calmodulin-like domain } \\
\text { protein kinase isoenzyme } \beta\end{array}$ & U69173 & $1.63 \mathrm{E}+02$ & 5 & 56.9 & 5.4 & 55.2 & 5.3 & No \\
\hline 21 & $3.3 \pm 0.5(0.042)$ & $S$-adenosylmethionine synthetase 3 & AW100184 & $9.07 \mathrm{E}+02$ & 4 & 51.5 & 5.6 & 39.5 & 6.2 & Yes \\
\hline 23 & $2.6 \pm 0.4(0.012)$ & $S$-adenosylmethionine synthetase 3 & AW100184 & $9.07 \mathrm{E}+02$ & 4 & 49.6 & 5.5 & 39.5 & 6.2 & Yes \\
\hline 57 & $2.2 \pm 0.1(0.023)$ & Unknown & AI441946 & $3.37 \mathrm{E}+03$ & 4 & 33.8 & 4.4 & na & na & Yes \\
\hline 69 & $2.4 \pm 0.2(0.025)$ & Ascorbate peroxidase 2 (APx2) & U56634 & $1.27 \mathrm{E}+08$ & 10 & 29.3 & 5.9 & 27.1 & 5.7 & No \\
\hline 16 & $1.7 \pm 0.2(0.070)$ & Enolase & AY496909 & $1.21 \mathrm{E}+05$ & 8 & 56.9 & 5.5 & 47.7 & 5.3 & Yes \\
\hline 20 & $1.5 \pm 0.2(0.150)$ & $\begin{array}{l}\text { Late embryogenesis abundant (LEA) } \\
\text { protein }\end{array}$ & M80664 & $8.85 \mathrm{E}+05$ & 14 & 52.7 & 4.8 & 50.6 & 6.3 & Yes \\
\hline 66 & $1.8 \pm 0.3(0.043)$ & Stem 31-kDa glycoprotein precursor & M37529 & $4.77 \mathrm{E}+02$ & 5 & 30.6 & 6.5 & 29.3 & 6.7 & No \\
\hline 68 & $1.9 \pm 0.4(0.105)$ & Ascorbate peroxidase & L10292 & $7.95 \mathrm{E}+04$ & 8 & 29.4 & 5.6 & 27.1 & 5.5 & No \\
\hline 71 & $1.5 \pm 0.2(0.173)$ & 28-kDa protein & M37530 & $2.50 \mathrm{E}+04$ & 8 & 28.9 & 9.5 & 29.1 & 8.8 & Yes \\
\hline 41 & $0.5 \pm 0.1(0.026)$ & Unknown & BE800877 & $1.14 \mathrm{E}+03$ & 6 & 37.0 & 4.9 & na & na & Yes \\
\hline 73 & $0.3 \pm 0.1(0.048)$ & Glutathione $S$-transferase GST8 & AF243363 & $7.58 \mathrm{E}+04$ & 8 & 27.9 & 5.6 & 25.7 & 5.8 & No \\
\hline 32 & $0.6 \pm 0.1(0.017)$ & $\begin{array}{l}\text { Polygalacturonase isoenzyme } 1 \beta \\
\text { subunit precursor }\end{array}$ & AW308789 & $1.17 \mathrm{E}+03$ & 8 & 42.8 & 6.4 & na & na & No \\
\hline 33 & $0.5 \pm 0.0(0.060)$ & Unknown & AW703975 & $2.07 \mathrm{E}+03$ & 8 & 42.0 & 6.1 & na & na & Yes \\
\hline 24 & $1.1 \pm 0.2(0.735)$ & $\begin{array}{l}\text { NADP-specific isocitrate } \\
\text { dehydrogenase (idh1) }\end{array}$ & L12157 & $1.59 \mathrm{E}+03$ & 10 & 48.9 & 6.0 & 49.1 & 6.1 & Yes \\
\hline 38 & $1.1 \pm 0.1(0.430)$ & $\begin{array}{l}\text { Oxygen-evolving enhancer protein } 2 \\
\text { precursor }\end{array}$ & AI759927 & $1.33 \mathrm{E}+03$ & 7 & 39.1 & 6.1 & 28.0 & 8.3 & Yes \\
\hline 65 & $1.2 \pm 0.2(0.354)$ & Caffeoyl-CoA $O$-methyltransferase & AI939180 & $1.22 \mathrm{E}+03$ & 5 & 31.5 & 5.3 & 28.0 & 5.6 & Yes \\
\hline 76 & $1.2 \pm 0.1(0.182)$ & Chalcone isomerase & AF276302 & $4.46 \mathrm{E}+06$ & 10 & 25.7 & 6.5 & 23.3 & 6.2 & No \\
\hline 87 & $1.0 \pm 0.4(0.826)$ & Cyclophilin & AF456323 & $1.17 \mathrm{E}+04$ & 8 & 20.0 & 9.6 & 18.2 & 8.7 & No \\
\hline
\end{tabular}

${ }^{\text {a }}$ Candidate proteins for 23 of the original 96 spots picked for MALDI-TOF MS analysis. Spots without positive identifications or spots with less than four peptide matches and a MOWSE score $<200$ were omitted.

${ }^{\mathrm{b}}$ The relative fold change of each spot vs. stripped roots, together with standard errors; Unique $=$ no corresponding spot in roots. The Student's $t$ test was employed to further test whether there was significant difference $(p<0.05)$ between root hairs and stripped roots; relative fold changes are averaged values of triplicate experiments],

${ }^{\mathrm{c}}$ MOWSE $=$ molecular weight search score, $\mathrm{PMed}=$ the number of MALDI-TOF MS peptides matched, E-MW $=$ experimental molecular weight, E-pI $=$ experimental isoelectric point, $\mathrm{T}-\mathrm{MW}=$ theoretical molecular weight, and T-pI $=$ theoretical isoelectric point. The IntelliCal column indicates whether the hit was confirmed by IntelliCal. $\mathrm{Na}=$ no full-length gene or protein available in the database. 
tion. Examples include lipoxygenases (Porta and Rocha-Sosa 2002), agglutinin or lectin (Bauchrowitz et al. 1996; Bohlool and Schmidt 1974; Halverson and Stacey 1985; Hirsch 1999), phenylalanine-ammonia lyase (Estabrook and SenguptaGopalan 1991), actin (Dantan-Gonzalez et al. 2001; De Ruijter et al. 1999), and ascorbate peroxidase (Iturbe-Ormaetxe et al.
2001; Matamoros et al. 2003). The identification of these proteins serves as useful internal controls to validate the experimental system.

However, in addition to these previously identified proteins, the current study also identified some new proteins (Tables 2 and 3; e.g., phospholipase D and phosphoglucomutase) that

Table 2. Proteins tentatively identified by tandem mass spectrometry (MS/MS) from soybean root hairs after Bradyrhizobium japonicum infection ${ }^{\mathrm{a}}$

\begin{tabular}{|c|c|c|c|c|c|c|c|c|c|c|c|c|}
\hline \multirow[b]{2}{*}{ Spot } & \multirow[b]{2}{*}{ Top Hit } & \multirow[b]{2}{*}{ Organism $^{b}$} & \multirow[b]{2}{*}{ GenBank } & \multirow[b]{2}{*}{$\mathbf{P}^{\mathbf{b}}$} & \multirow[b]{2}{*}{ E-pI } & \multirow[b]{2}{*}{ E-MW } & \multirow[b]{2}{*}{ T-pI } & \multirow[b]{2}{*}{ T-MW } & \multicolumn{4}{|c|}{ Fold Change at Time ${ }^{c}$} \\
\hline & & & & & & & & & $\mathbf{0}$ & 3 & 6 & 12 \\
\hline 4 & $\begin{array}{l}\text { Endopeptidase Clp ATP- } \\
\text { binding chain, Chloroplast }\end{array}$ & Pisum sativum & S31164 & 6 & 5.4 & 89.9 & 6.5 & 102.7 & $\begin{array}{l}1.0 \pm 0.5 \\
(0.679)\end{array}$ & $\begin{array}{l}1.2 \pm 0.1 \\
(0.273)\end{array}$ & $\begin{array}{l}1.4 \pm 0.3 \\
(0.435)\end{array}$ & $\begin{array}{l}5.0 \pm 0.6 \\
(0.040)\end{array}$ \\
\hline 5 & Phospholipase D1 & $\begin{array}{l}\text { Craterostigma } \\
\text { plantagineum }\end{array}$ & CAB43063 & 2 & 5.5 & 89.1 & 5.2 & 91.7 & $\begin{array}{l}0.7 \pm 0.2 \\
(0.385)\end{array}$ & $\begin{array}{l}1.7 \pm 0.5 \\
(0.395)\end{array}$ & $\begin{array}{l}3.6 \pm 0.6 \\
(0.043)\end{array}$ & $\begin{array}{l}1.2 \pm 0.2 \\
(0.406)\end{array}$ \\
\hline 6 & $\begin{array}{l}\text { Endopeptidase Clp ATP- } \\
\text { binding chain, Chloroplast }\end{array}$ & $P$. sativum & S31164 & 3 & 5.4 & 89.0 & 6.5 & 102.7 & $\begin{array}{l}2.8 \pm 1.6 \\
(0.180)\end{array}$ & $\begin{array}{l}1.4 \pm 0.3 \\
(0.271)\end{array}$ & $\begin{array}{l}1.5 \pm 0.2 \\
(0.169)\end{array}$ & $\begin{array}{l}0.5 \pm 0.1 \\
(0.047)\end{array}$ \\
\hline 7 & Lipoxygenase & Glycine $\max$ & T06354 & 4 & 5.9 & 88.2 & 5.7 & 94.9 & $\begin{array}{l}0.4 \pm 0.2 \\
(0.062)\end{array}$ & $\begin{array}{l}1.5 \pm 0.5 \\
(0.381)\end{array}$ & nd & $\begin{array}{l}1.2 \pm 0.2 \\
(0.566)\end{array}$ \\
\hline 9 & Vesicular fusion protein & $\begin{array}{c}\text { Nicotiana } \\
\text { tabacum }\end{array}$ & T02996 & 4 & 5.9 & 71.1 & 5.8 & 80.9 & $\begin{array}{l}0.9 \pm 0.2 \\
(0.565)\end{array}$ & $\begin{array}{l}1.0 \pm 0.3 \\
(0.844)\end{array}$ & $\begin{array}{l}1.4 \pm 0.3 \\
(0.327)\end{array}$ & $\begin{array}{l}0.4 \pm 0.1 \\
(0.033)\end{array}$ \\
\hline 10 & Phenylalanine-ammonia lyase & G. $\max$ & P27991 & 7 & 5.9 & 70.0 & 6.0 & 77.7 & $\begin{array}{l}2.0 \pm 1.0 \\
(0.395)\end{array}$ & $\begin{array}{l}2.6 \pm 0.2 \\
(0.031)\end{array}$ & $\begin{array}{l}1.6 \pm 0.5 \\
(0.318)\end{array}$ & $\begin{array}{l}0.9 \pm 0.1 \\
(0.300)\end{array}$ \\
\hline 13 & Phosphoglucomutase & P. sativum & Q9SM60 & 5 & 5.4 & 65.9 & 5.5 & 63.3 & $\begin{array}{l}2.1 \pm 0.6 \\
(0.215)\end{array}$ & $\begin{array}{l}2.9 \pm 1.5 \\
(0.219)\end{array}$ & $\begin{array}{l}6.2 \pm 2.3 \\
(0.021)\end{array}$ & $\begin{array}{l}0.7 \pm 0.3 \\
(0.169)\end{array}$ \\
\hline 15 & $\begin{array}{l}\text { Putative heat shock } 70 \mathrm{kDa} \\
\text { protein mitochondrial } \\
\text { precursor }\end{array}$ & Oryza sativa & AAO17017 & 10 & 5.3 & 61.9 & 5.5 & 70.4 & $\begin{array}{l}1.0 \pm 0.1 \\
(0.729)\end{array}$ & $\begin{array}{l}1.0 \pm 0.1 \\
(0.900)\end{array}$ & $\begin{array}{l}2.4 \pm 0.4 \\
(0.035)\end{array}$ & $\begin{array}{l}0.8 \pm 0.2 \\
(0.384)\end{array}$ \\
\hline 17 & $\begin{array}{l}\text { 2,3-bisphosphoglycerate- } \\
\text { independent } \\
\text { phosphoglycerate mutase }\end{array}$ & N. tabacum & P35494 & 8 & 5.7 & 58.1 & 6.0 & 61.1 & $\begin{array}{l}1.3 \pm 0.3 \\
(0.385)\end{array}$ & $\begin{array}{l}1.7 \pm 0.3 \\
(0.091)\end{array}$ & $\begin{array}{l}1.6 \pm 0.2 \\
(0.104)\end{array}$ & $\begin{array}{l}0.5 \pm 0.1 \\
(0.037)\end{array}$ \\
\hline 18 & Chaperonin & $\begin{array}{l}\text { Arabidopsis } \\
\text { thaliana }\end{array}$ & NP_187789 & 3 & 6.4 & 56.5 & 6.0 & 59.8 & $\begin{array}{l}0.7 \pm 0.3 \\
(0.335)\end{array}$ & $\begin{array}{l}0.5 \pm 0.1 \\
(0.049)\end{array}$ & nd & $\begin{array}{l}0.9 \pm 0.2 \\
(0.625)\end{array}$ \\
\hline 19 & $\begin{array}{l}\text { Mitochondrial processing } \\
\text { peptidase beta subunit }\end{array}$ & Cucumis melo & AAK07827 & 9 & 6.4 & 55.4 & 6.6 & 58.9 & $\begin{array}{l}1.2 \pm 0.2 \\
(0.412)\end{array}$ & $\begin{array}{l}2.1 \pm 0.5 \\
(0.175)\end{array}$ & $\begin{array}{l}0.4 \pm 0.1 \\
(0.032)\end{array}$ & $\begin{array}{l}0.9 \pm 0.2 \\
(0.593)\end{array}$ \\
\hline 21 & $\begin{array}{l}\text { Mitochondrial processing } \\
\text { peptidase alpha subunit } \\
\text { precursor }\end{array}$ & O. sativa & BAB55500 & 3 & 5.0 & 53.5 & 8.6 & 94.6 & $\begin{array}{l}2.1 \pm 0.4 \\
(0.060)\end{array}$ & $\begin{array}{l}0.8 \pm 0.2 \\
(0.479)\end{array}$ & $\begin{array}{l}1.0 \pm 0.2 \\
(0.725)\end{array}$ & nd \\
\hline 22 & Actin & G. $\max$ & AAB40077 & 10 & 5.1 & 43.2 & 5.4 & 37.2 & $\begin{array}{l}1.1 \pm 0.3 \\
(0.891)\end{array}$ & $\begin{array}{l}1.2 \pm 0.4 \\
(0.728)\end{array}$ & $\begin{array}{l}1.1 \pm 0.2 \\
(0.685)\end{array}$ & $\begin{array}{l}0.3 \pm 0.1 \\
(0.023)\end{array}$ \\
\hline 23 & $\begin{array}{l}\text { Isocitrate dehydrogenase } \\
\text { (NADP) }\end{array}$ & G. $\max$ & S33612 & 12 & 6.0 & 42.6 & 6.3 & 50.2 & $\begin{array}{l}6.7 \pm 3.2 \\
(0.235)\end{array}$ & $\begin{array}{l}1.3 \pm 0.1 \\
(0.1390\end{array}$ & $\begin{array}{l}0.7 \pm 0.3 \\
(0.441)\end{array}$ & $\begin{array}{l}2.2 \pm 0.5 \\
(0.047)\end{array}$ \\
\hline 24 & $\begin{array}{l}\text { Cinnamyl-alcohol } \\
\text { dehydrogenase }\end{array}$ & Medicago sativa & P31656 & 4 & 5.6 & 40.3 & 5.6 & 38.9 & $\begin{array}{l}0.9 \pm 0.2 \\
(0.609)\end{array}$ & $\begin{array}{l}1.2 \pm 0.1 \\
(0.139)\end{array}$ & $\begin{array}{l}1.5 \pm 0.4 \\
(0.248)\end{array}$ & $\begin{array}{l}0.5 \pm 0.1 \\
(0.028)\end{array}$ \\
\hline 25 & L-ascorbate peroxidase 1 & G. $\max$ & T07056 & 5 & 5.8 & 26.5 & 5.6 & 27.1 & $\begin{array}{l}0.4 \pm 0.2 \\
(0.124)\end{array}$ & $\begin{array}{l}1.6 \pm 0.4 \\
(0.206)\end{array}$ & $\begin{array}{l}0.4 \pm 0.1 \\
(0.032)\end{array}$ & $\begin{array}{l}1.0 \pm 0.2 \\
(0.807)\end{array}$ \\
\hline 26 & $\begin{array}{l}\text { Disease resistance response } \\
\text { protein-related/dirigent } \\
\text { protein-related }\end{array}$ & A. thaliana & NP_175917 & 2 & 5.6 & 20.1 & 9.4 & 20.6 & $\begin{array}{l}1.7 \pm 0.5 \\
(0.274)\end{array}$ & $\begin{array}{l}1.2 \pm 0.1 \\
(0.262)\end{array}$ & $\begin{array}{l}3.9 \pm 0.2 \\
(0.022)\end{array}$ & $\begin{array}{l}1.7 \pm 0.5 \\
(0.278)\end{array}$ \\
\hline 1 & & & & & 5.7 & 101 & & & $\begin{array}{l}1.2 \pm 0.2 \\
(0.637)\end{array}$ & $\begin{array}{l}2.0 \pm 0.6 \\
(0.428)\end{array}$ & $\begin{array}{l}1.4 \pm 0.2 \\
(0.210)\end{array}$ & $\begin{array}{l}2.3 \pm 0.1 \\
(0.023)\end{array}$ \\
\hline 2 & & & & & 5.6 & 94.9 & & & $\begin{array}{l}1.0 \pm 0.2 \\
(0.846)\end{array}$ & $\begin{array}{l}5.6 \pm 2.1 \\
(0.044)\end{array}$ & $\begin{array}{l}1.9 \pm 0.1 \\
(0.060)\end{array}$ & $\begin{array}{l}0.9 \pm 0.2 \\
(0.550)\end{array}$ \\
\hline 3 & & & & & 6.9 & 91.2 & & & $\begin{array}{l}0.3 \pm 0.1 \\
(0.037)\end{array}$ & $\begin{array}{l}1.6 \pm 0.5 \\
(0.324)\end{array}$ & $\begin{array}{l}1.8 \pm 0.2 \\
(0.101)\end{array}$ & $\begin{array}{l}1.3 \pm 0.5 \\
(0.653)\end{array}$ \\
\hline 8 & & & & & 6.0 & 85.1 & & & $\begin{array}{l}1.1 \pm 0.3 \\
(0.876)\end{array}$ & $\begin{array}{l}1.1 \pm 0.1 \\
(0.642)\end{array}$ & $\begin{array}{l}3.4 \pm 0.8 \\
(0.042)\end{array}$ & $\begin{array}{l}1.2 \pm 0.2 \\
(0.365)\end{array}$ \\
\hline 11 & & & & & 6.9 & 70.0 & & & $\begin{array}{l}1.0 \pm 0.1 \\
(0.670)\end{array}$ & $\begin{array}{l}1.4 \pm 0.3 \\
(0.245)\end{array}$ & $\begin{array}{l}2.3 \pm 0.1 \\
(0.045)\end{array}$ & $\begin{array}{l}1.8 \pm 0.3 \\
(0.051)\end{array}$ \\
\hline 12 & & & & & 5.4 & 68.2 & & & $\begin{array}{l}1.3 \pm 0.4 \\
(0.635)\end{array}$ & $\begin{array}{l}2.0 \pm 0.3 \\
(0.055)\end{array}$ & $\begin{array}{l}4.2 \pm 0.9 \\
(0.035)\end{array}$ & $\begin{array}{l}2.6 \pm 0.6 \\
(0.068)\end{array}$ \\
\hline 14 & & & & & 5.1 & 63.0 & & & $\begin{array}{l}1.1 \pm 0.1 \\
(0.800)\end{array}$ & $\begin{array}{l}0.8 \pm 0.2 \\
(0.281)\end{array}$ & $\begin{array}{l}2.6 \pm 0.6 \\
(0.049)\end{array}$ & $\begin{array}{l}0.8 \pm 0.1 \\
(0.271)\end{array}$ \\
\hline 16 & & & & & 6.1 & 61.2 & & & $\begin{array}{l}1.1 \pm 0.2 \\
(0.651)\end{array}$ & $\begin{array}{l}1.2 \pm 0.2 \\
(0.638)\end{array}$ & $\begin{array}{l}5.4 \pm 1.1 \\
(0.036)\end{array}$ & $\begin{array}{l}0.8 \pm 0.1 \\
(0.254)\end{array}$ \\
\hline 20 & & & & & 6.5 & 54.3 & & & $\begin{array}{l}1.0 \pm 0.1 \\
(0.649)\end{array}$ & $\begin{array}{l}0.7 \pm 0.3 \\
(0.457)\end{array}$ & $\begin{array}{l}1.0 \pm 0.1 \\
(0.896)\end{array}$ & $\begin{array}{l}0.5 \pm 0.1 \\
(0.029)\end{array}$ \\
\hline
\end{tabular}

${ }^{a}$ Compared with the water control treatment. Out of the original 26 spots, 17 were picked for the MS/MS analysis. Spots without positive identifications or spots with $<2$ peptide matches were also included at the end of the table.

${ }^{\mathrm{b}}$ Organism indicates the origin of the hit, $\mathrm{P}=$ the number of MS peptides matched, E-pI $=$ experimental isoelectric point, E-MW $=$ experimental molecular weight, T-pI = theoretical isoelectric point, and T-MW = theoretical molecular weight.

${ }^{\mathrm{c}}$ Fold change at time [(h) $\pm \mathrm{SE}$ ( $p$ value)] shows relative fold change vs. water-treated samples at each timepoint \pm standard errors. The Student's $t$ test was employed to further test whether there was significant difference $(p<0.05)$ between bacterial-treated root hairs and water-treated root hairs at each timepoint. The $p$ values were included in parentheses; relative fold changes are averaged values of triplicate experiments. nd indicates a bad gel region and therefore no expression intensity. 
appeared to respond to B. japonicum inoculation. Phospholipase $\mathrm{D}$ is of particular interest, since it may play an important role in nodulation through its function in lipid signaling pathways (den Hartog et al. 2001). The activation of phospholipase D was previously correlated with microtubule reorganization in living plant cells (Dhonukshe et al. 2003), and therefore, it may play this role during root-hair deformation induced by compatible rhizobia (den Hartog et al. 2001). Phosphoglucomutase, a key enzyme required for the formation of UDPglucose and ADP-glucose, the sugar donors for the biosynthesis of glucose-containing polysaccharides, is known to be required by rhizobia for nodulation (Lepek et al. 2002). In plants, phosphoglucomutase plays a significant role in the partitioning of stored carbon. In starch-storing plants, multiple isoforms of phosphoglucomutase often exist, since the enzymes are required both in the cytoplasm and in the plastids. The enzymes provide the substrate phosphoglucose for starch synthesis or other pathways (Harrison et al. 2000). Therefore, phosphoglucomutase may play a role in the Rhizobium-legume interaction by affecting the availability of host phosphoglucose to the rhizobium.

Also of specific interest to the symbiosis is the apparent induction of soybean lectin by B. japonicum inoculation. The involvement of lectins in legume nodulation has a controversial history. Early work suggested that lectins could attach the rhizobia to the root-hair surface (Halverson and Stacey 1985). In more recent work, Díaz and associates (1989) showed that expression of the pea lectin in clover resulted in infection of clover by $R$. leguminosarum, normal symbiont of pea. This work was extended by van Rhijn and associates (1998), who showed that expression of the soybean lectin in Lotus corniculatus could result in infection of this plant by B. japonicum. A lectin gene was previously shown to be induced in $M$. truncatula one week after infection by its compatible symbiont Sinorhizobium meliloti but was not shown to be induced early ( $<7$ days) in the infection process (Mitra and Long 2004). Our current data showing a significant induction of lectin within the root-hair cell within $18 \mathrm{~h}$ of inoculation argues for an important, early role for lectins in the soybean root-hair infection process.

The induction of actin expression after inoculation is also interesting, given the known rearrangements of the cytoskeleton that occur at the root-hair tip during the early stages of infection (Allen and Bennett 1996; Cardenas et al. 1998, 2003; Ketelaar and Emons 2001; Lhuissier et al. 2001). Likewise, induction of the vesicular fusion protein could be explained by the need for vesicular fusion to the root-hair membrane to maintain root-hair growth (Allen and Bennett 1996; Miller et al. 1997).

\section{Protein identifications can be achieved with organisms without complete sequenced genomes but with a large collection of EST sequences.}

The success rate of positive identifications using PMF (peptide mass fingerprint) data, even MS/MS data, appears to be directly correlated with genome sequence availability from the species studied at the time of searching. For example, with the complete sequenced genomes, such as Arabidopsis and rice, the positive identification or matching by PMF can reach $60 \%$ (Heazlewood and Millar 2003). However, when such sequences are incomplete or absent, EST sequences can be employed with certain success rates. For example, in the case of M. truncatula, which has a partially sequenced genome and a large collection of EST sequences, the positive identification or matching rate using PMF data reached 55\% (Watson et al. 2003). Even in a few cases, a certain degree of success in identifying putative candidates can be achieved by querying PMF data against other organisms (Mathesius et al. 2002). Recently, Kwon and associates (2003) demonstrated that EST databases can be used reliably for high-throughput proteomic studies in an organism without genome information using MS/MS data.

Soybean has a very large genome, approximately $1,100 \mathrm{Mb}$, and little genomic sequence information is available. However, a large collection of EST sequences $(>300,000)$ is available for this organism. The current study is one of the few attempts to use proteomics tools to identify proteins from this organism. By querying the Soybean UniGene EST database using Protein Prospector, the positive identification or matching rate using tryptic peptide masses from MALDI-TOF analyses was approximately $24 \%$, using conservative cutoff values. In the case of MS/MS data, 11 of 26 proteins could be matched to known soybean proteins, with the remainder identified by significant matches to other plant proteins. The overall positive identification or matching rate using MS/MS was approximately $70 \%$. Therefore, the current study suggests that MS/MS data is preferred for identification of soybean proteins, but that peptide mass data can also often be used to identify soybean proteins.
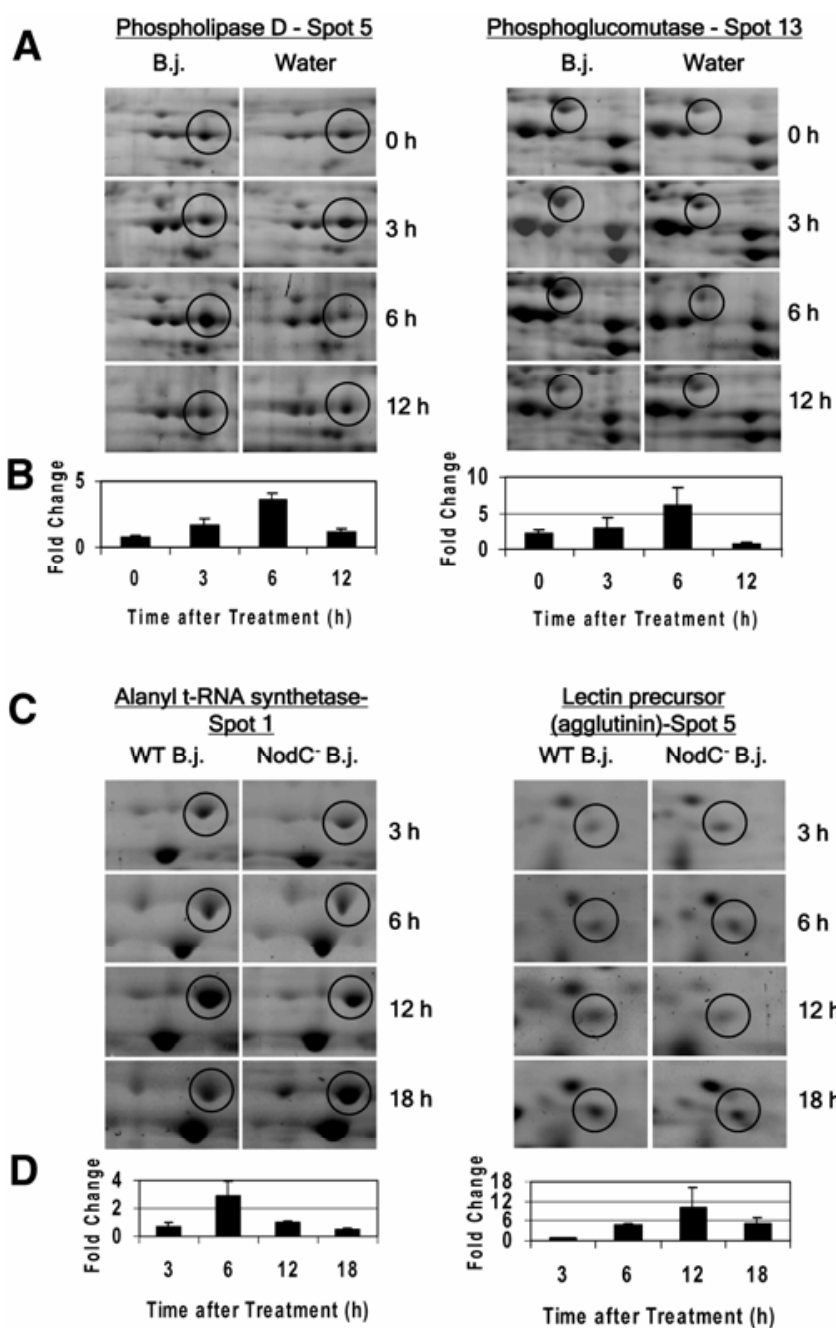

Fig. 3. Examples of proteins affected by Bradyrhizobium japonicum infection. $\mathbf{A}$ and B, Highlights of two examples from the B. japonicum-water experiment: spot 5, phospholipase D, and spot 13, phosphoglucomtase. C and D, Highlights of two examples from the wild-type/ $\mathrm{NodC}^{-} B . j a-$ ponicum experiment: spot 1, alanyl t-RNA synthetase; and spot 5 , lectin precursor (agglutinin). The bar graphs show the relative fold changes at each timepoint by comparing with the corresponding control for the highlighted spots, together with standard errors. 
However, even with the complete sequenced genome, such as Arabidopsis and rice, the positive identification or matching rate using peptide mass data is not even close to $100 \%$ (only approximately 60\%) (Heazlewood and Millar 2003). The lack of a high matching rate is probably due to misannotations and genome or EST sequencing errors, comigrated proteins, and incomplete trypsin digestion. In addition, posttranslational modifications could be another reason for the lack of a high matching rate. Additional bioinformatics tools may be helpful to reduce false negatives and positives, increasing the utility of available sequence resources. One recent endeavor in this direction was described by Ganapathy and colleagues (2004).

\section{Concluding remarks.}

Prior to embarking on a larger, more detailed functional genomic study of the symbiotic interaction between soybean and its symbiont B. japonicum, we tested the feasibility of using proteomics tools on a single-celled tissue-soybean root hairs. Enough pure root hairs could be obtained easily for proteomic analysis. The current study succeeded in identifying a number of new root-hair proteins that were responsive to $B$. japonicum infection in addition to some proteins previously known to be responsive. The current study also identified a number of proteins that were unique or more abundant in root hairs. The identified proteins will provide new leads for further study of the legume-Rhizobium symbiotic interactions. Therefore, soybean root hairs are a good tissue for further proteomic study of this symbiotic interaction.

\section{MATERIALS AND METHODS}

Bacterial culture, plant growth, and root hair preparation.

B. japonicum USDA110 was grown at $30^{\circ} \mathrm{C}$ in RDY medium (So et al. 1987) with the antibiotic chloramphenicol (40 $\mu \mathrm{g} / \mathrm{ml}$ ) for 4 days, was spun down at 5,000 rpm for $10 \mathrm{~min}$, was washed with sterile water, and was resuspended in sterile water to an optical density at $600 \mathrm{~nm}$ of approximately 0.9 for root inoculation. The B. japonicum NodC $^{-}$mutant nodC::Tn5 (Loh and Stacey 2001) was grown in RDY with chloramphenicol $(40 \mu \mathrm{g} / \mathrm{ml})$, kanamycin $(100 \mu \mathrm{g} / \mathrm{ml})$, and streptomycin $(100$ $\mu \mathrm{g} / \mathrm{ml})$.

Soybean seeds (Glycine max [L.] Merr., cv. Williams 82) were surface-sterilized by sequential treatment with $20 \%$ Chlorox for $10 \mathrm{~min}$, sterile water for five times, $0.01 \mathrm{M} \mathrm{HCl}$ for $10 \mathrm{~min}$, and sterile water for five times. The sterilized seeds were planted on nitrogen-free B \& D agar medium (Broughton and Dilworth 1971) in large glass petri dishes and were incubated in the dark at $25^{\circ} \mathrm{C}$ for four days. Four-day-old seedlings were sprayed with water or the above resuspended wild-type or $\mathrm{NodC}^{-}$mutant $B$. japonicum resuspension until all the seedlings appeared evenly wet. The treated seedlings were returned to the original growth chamber for the incubation times indicated.

Root-hair isolation was essentially as described by Bucher and associates (1997). Briefly, after a certain period of treatment, roots were removed from soybean seedlings and immediately frozen in liquid nitrogen. Root hairs were physically sheared off roots by gentle stirring $(15 \mathrm{~min})$ and were separated from remaining roots by filtering through a wire mesh with a

Table 3. Proteins identified by matrix-assisted laser desorption ionization time-of-flight (MALDI-TOF) mass spectrometry (MS) and MS/MS from soybean root hairs after B. japonicum infection ${ }^{\mathrm{a}}$

\begin{tabular}{|c|c|c|c|c|c|c|c|c|c|c|c|c|c|}
\hline \multirow[b]{2}{*}{ Spot } & \multirow[b]{2}{*}{ Top Hit } & \multirow[b]{2}{*}{ Organism } & \multirow[b]{2}{*}{ GenBank } & \multirow[b]{2}{*}{$\mathbf{P}^{\mathbf{b}}$} & \multirow[b]{2}{*}{ MM } & \multirow[b]{2}{*}{ E-pI } & \multirow[b]{2}{*}{ E-MW } & \multirow[b]{2}{*}{ T-pI } & \multirow[b]{2}{*}{ T-MW } & \multicolumn{4}{|c|}{ Fold change at time ${ }^{c}$} \\
\hline & & & & & & & & & & 3 & 6 & 12 & 18 \\
\hline 2 & Lipoxygenase & G. $\max$ & T06354 & 22 & $158(64)$ & 6.0 & 98.2 & 5.7 & 94.9 & $\begin{array}{l}0.9 \pm 0.1 \\
(0.582)\end{array}$ & $\begin{array}{l}1.7 \pm 0.6 \\
(0.651)\end{array}$ & $\begin{array}{l}0.2 \pm 0.1 \\
(0.015)\end{array}$ & $\begin{array}{l}0.8 \pm 0.2 \\
(0.380)\end{array}$ \\
\hline 5 & $\begin{array}{l}\text { Lectin precursor } \\
\text { (agglutinin) }\end{array}$ & G. $\max$ & P05046 & 5 & $73(75)$ & 5.3 & 32.3 & 5.7 & 30.9 & $\begin{array}{l}0.8 \pm 0.2 \\
(0.511)\end{array}$ & $\begin{array}{l}4.7 \pm 0.8 \\
(0.049)\end{array}$ & $\begin{array}{l}10.2 \pm 6.1 \\
(0.135)\end{array}$ & $\begin{array}{l}5.1 \pm 2.1 \\
(0.099)\end{array}$ \\
\hline 7 & Trypsin inhibitor & G. $\max$ & 1AVX_B & 11 & $130(64)$ & 4.6 & 20.0 & 4.8 & 19.1 & $\begin{array}{l}4.9 \pm 2.2 \\
(0.036)\end{array}$ & $\begin{array}{l}0.3 \pm 0.2 \\
(0.038)\end{array}$ & $\begin{array}{l}1.0 \pm 0.1 \\
(0.481)\end{array}$ & $\begin{array}{l}1.0 \pm 0.1 \\
(0.308)\end{array}$ \\
\hline 10 & $\begin{array}{l}\text { Glycine-rich RNA- } \\
\text { binding protein }\end{array}$ & G. $\max$ & AAD48471 & 14 & $191(64)$ & 6.5 & 19.3 & 6.6 & 15.8 & $\begin{array}{l}1.0 \pm 0.1 \\
(0.897)\end{array}$ & $\begin{array}{l}4.3 \pm 1.3 \\
(0.015)\end{array}$ & $\begin{array}{l}0.4 \pm 0.1 \\
(0.073)\end{array}$ & $\begin{array}{l}2.0 \pm 0.2 \\
(0.134)\end{array}$ \\
\hline 1 & $\begin{array}{l}\text { Alanyl t-RNA } \\
\text { synthetase, mito- } \\
\text { chondrial precursor }\end{array}$ & G. $\max$ & AW100399 & 3 & $\ldots$ & 5.7 & 113.2 & na & na & $\begin{array}{l}0.8 \pm 0.3 \\
(0.503)\end{array}$ & $\begin{array}{l}2.9 \pm 0.2 \\
(0.023)\end{array}$ & $\begin{array}{l}1.0 \pm 0.1 \\
(0.848)\end{array}$ & $\begin{array}{l}0.5 \pm 0.2 \\
(0.309)\end{array}$ \\
\hline 3 & $\begin{array}{l}\text { Phenylalanine- } \\
\text { ammonia lyase } 1\end{array}$ & G. $\max$ & P27991 & 3 & $\ldots$ & 6.0 & 86.9 & 6.0 & 77.7 & $\begin{array}{l}1.9 \pm 1.0 \\
(0.547)\end{array}$ & $\begin{array}{l}1.0 \pm 0.1 \\
(0.976)\end{array}$ & $\begin{array}{l}3.8 \pm 0.6 \\
(0.045)\end{array}$ & $\begin{array}{l}0.9 \pm 0.1 \\
(0.527)\end{array}$ \\
\hline 6 & $\begin{array}{l}\text { Chalcone-flavonone } \\
\text { isomerase A }\end{array}$ & G. $\max$ & AI442388 & 3 & $\ldots$ & 4.9 & 26.0 & 5.0 & 35.5 & $\begin{array}{l}0.7 \pm 0.3 \\
(0.352)\end{array}$ & $\begin{array}{l}0.7 \pm 0.2 \\
(0.268)\end{array}$ & $\begin{array}{l}0.5 \pm 0.1 \\
(0.049)\end{array}$ & $\begin{array}{l}1.2 \pm 0.1 \\
(0.246)\end{array}$ \\
\hline 8 & $\begin{array}{l}\text { Probable enoyl-(acyl- } \\
\text { carrier-protein) } \\
\text { reductase (NADH2) }\end{array}$ & G. $\max$ & T03735 & 4 & $\ldots$ & 5.9 & 37.0 & 9.1 & 39.9 & $\begin{array}{l}0.4 \pm 0.1 \\
(0.138)\end{array}$ & $\begin{array}{l}1.0 \pm 0.1 \\
(0.919)\end{array}$ & $\begin{array}{l}1.8 \pm 0.3 \\
(0.058)\end{array}$ & $\begin{array}{l}1.3 \pm 0.1 \\
(0.095)\end{array}$ \\
\hline 9 & $\begin{array}{l}\text { Similar to early nodulin } \\
18 \text { (Vicia faba } \\
\text { NCBInr 11602751) }\end{array}$ & G. $\max$ & AI960983 & 10 & $\ldots$ & 6.0 & 20.0 & na & na & $\begin{array}{l}0.3 \pm 0.1 \\
(0.052)\end{array}$ & $\begin{array}{l}0.6 \pm 0.4 \\
(0.337)\end{array}$ & $\begin{array}{l}1.4 \pm 0.4 \\
(0.456)\end{array}$ & $\begin{array}{l}0.9 \pm 0.1 \\
(0.426)\end{array}$ \\
\hline 11 & $\begin{array}{l}\text { Similar to porcine } 40 \mathrm{~S} \\
\text { ribosomal protein } \\
\text { S12 (Swiss-prot } \\
\text { P46405) }\end{array}$ & G. $\max$ & AW101622 & 4 & $\ldots$ & 5.4 & 19.1 & na & na & $\begin{array}{l}0.4 \pm 0.2 \\
(0.150)\end{array}$ & $\begin{array}{l}1.1 \pm 0.2 \\
(0.716)\end{array}$ & $\begin{array}{l}7.2 \pm 2.7 \\
(0.037)\end{array}$ & $\begin{array}{l}1.2 \pm 0.2 \\
(0.596)\end{array}$ \\
\hline 4 & & $\ldots$ & $\ldots$ & $\ldots$ & $\ldots$ & 4.9 & 58.7 & $\ldots$ & $\ldots$ & $\begin{array}{l}1.0 \pm 0.2 \\
(0.704)\end{array}$ & $\begin{array}{l}0.3 \pm 0.1 \\
(0.028)\end{array}$ & $\begin{array}{l}1.0 \pm 0.1 \\
(0.671)\end{array}$ & $\begin{array}{l}1.9 \pm 0.4 \\
(0.151)\end{array}$ \\
\hline
\end{tabular}

${ }^{a}$ Compared with the NodC $^{-}$mutant. Out of the original 11 spots, 10 were picked for either MALDI-TOF MS or MS/MS analysis.

${ }^{\mathrm{b}} \mathrm{P}=$ the number of MALD-TOF MS or MS/MS peptides matched, MM = Mascot MOWSE scores for the top four spots with their corresponding significant scores in parentheses (hits with Mowse scores greater than this number are good candidates), E-pI = experimental isoelectric point, E-MW = experimental molecular weight, $\mathrm{T}-\mathrm{pI}=$ theoretical isoelectric point, and $\mathrm{T}-\mathrm{MW}=$ theoretical molecular weight.

${ }^{\mathrm{c}}$ Fold change at time $[\mathrm{h} \pm$ standard error $(p$ value $)]=$ relative fold change vs. control samples at each timepoint. The Student's $t$ test was employed to further test whether there was significant difference $(p<0.05)$ between treated root hairs and control root hairs at each timepoint. The $p$ values are included in parentheses. The relative fold changes are averaged values of triplicate experiments. na indicates that no full-length gene or protein was available for a spot, and therefore, the theoretical MW and $\mathrm{pI}$ values were omitted. 
hole size of approximately $250 \mu \mathrm{m}$. After evaporation of liquid nitrogen, root hairs were quickly weighed while frozen and were stored at $-80^{\circ} \mathrm{C}$ for later protein isolation. For each experiment, a minimum of three biological replicates were performed and analyzed.

\section{Protein preparation, 2-D gel electrophoresis, and gel imaging.}

Proteins were isolated according to Mooney and Thelen (2004) as adapted from Hurkman and Tanaka (1986). Protein concentrations were estimated according to Bradford (1976), using the Bio-Rad protein assay dye solution (Bio-Rad, Hercules, CA, U.S.A.). 2-D gel electrophoresis was conducted according to Mooney and Thelen (2004). Briefly, for the firstdimension separation, 24-cm IPG strips (linear $\mathrm{pH} 3$ to 10 or $\mathrm{pH} 4$ to 7, as indicated above) from Amersham (Amersham Bioscience, Piscataway, NJ, U.S.A.) were rehydrated with 1 $\mathrm{mg}$ of protein. Isoelectric focusing (IEF) was carried out in a Bio-Rad protein IEF cell. After focusing and reduction or alkylation, strips were loaded onto an 11 to $17 \%$ (wt/vol) gradient acrylamide gel for the second-dimension separation. Gels were stained with Coomassie brilliant blue G-250, followed by destaining. Gel images (8-bit .tif) were obtained using a scanning densitometer (Bio-Rad). Protein MW and pI values were estimated from the captured images according to the protein molecular weight markers and the $\mathrm{pH}$ gradient using Phoretix 2D software (Nonlinear Dynamics, Newcastle Upon Tyne, U.K.).

\section{Analysis of protein gel images using PDQuest.}

The analysis of protein 2-D images was conducted according to manufacturer's instructions using PDQuest software (Bio-Rad, Hercules, CA, U.S.A.). Briefly, the 2-D images in .tif format were imported into the software and necessary adjustments, including rotation and flipping, were made. Spots in the images were then detected and a matchset was created; spots across all the gel images in the matchset were automatically matched and normalized. The built-in method "total quantity in valid spots" was used for the normalization. In this normalization method, the raw quantity of each spot in a member gel is divided by the total quantity of all the spots in that gel that were included in the master. The alignment of spots across all the images in the matchset was further adjusted based on a number of selected landmarks. After pooling replicates, the relative change in protein levels between the treatment and control was represented by the ratio between them. Spots showing a $\geq 2$-fold induction or suppression by comparing with the control treatment were considered to be differentially regulated and were selected for further MS analysis. Most of these selections were also statistically significant $(p<$ 0.05 ) after the Student's $t$ test.

\section{Trypsin digestion, MALDI-TOF MS, MS/MS, and database searching.}

Protein spots were excised from the gels either manually with a 1.5-mm diameter spot picker (The Gel Company, San Francisco) or automatically using the GelPix (Genetix Limited, New Milton, Hampshire, U.K.). Gel plugs were destained with a minimum of three 15-min rinses with 1:1 (vol/vol) acetonitrile/0.1 M ammonium bicarbonate (aq), then were dehydrated with acetonitrile.

After thorough drying, the plugs were rehydrated in $30 \mu \mathrm{l}$ of a solution $(0.02$ to $0.03 \mu \mathrm{g} / \mu \mathrm{l})$ of modified porcine tosyl-Lphenylanine chloromethyl ketone (TPCK)-treated trypsin (Promega, Madison, WI, U.S.A.) in $0.05 \mathrm{M}$ aq. The gel plugs were subsequently digested in the trypsin solution at $37^{\circ} \mathrm{C}$ overnight. Digest solutions were pipetted from the gel plugs and the plugs were extracted twice with 600:300:100 (vol/vol/vol) acetonitrile/water/10\% trifluoroacetic acid. Extracts were pooled with the respective digest solutions, and the pools were dried in a centrifugal evaporator without heating. Alternatively, low protein concentration plugs were rehydrated in the trypsin solution for $1 \mathrm{~h}$ at $4^{\circ} \mathrm{C}$. Then, the trypsin solution was replaced with $10 \mu \mathrm{l} 0.05 \mathrm{M}$ aq, and digestion was continued for $1 \mathrm{~h}$ at $56^{\circ} \mathrm{C}$, according to Havlis and associates (2003). Accelerated digests were acidified with formic acid, and the gel plugs were extracted with $10 \mu \mathrm{l}$ of $0.02 \mathrm{M}$ aq, followed by three extractions $(10 \mu \mathrm{l}$ each) with a solution of acetonitrile/ water $/ 88 \%$ formic acid (600:350:50, vol/ $\mathrm{vol} / \mathrm{vol})$.

Dried digests from the above processed gel plugs were desalted on Millipore $\mathrm{C}_{18}$ Ziptips (Bedford, MA, U.S.A.). Each digest was reconstituted in 990:10 ( $\mathrm{vol} / \mathrm{vol}$ ) water/88\% formic acid and was loaded onto a prepared Ziptip by cycling the sample into and out of the tip 15 times. The Ziptip was washed with five $10-\mu l$ portions of sample reconstitution solvent before the adsorbed peptides were eluted from the Ziptip with 5 to 10 $\mu \mathrm{l}$ 700:290:10 (vol/vol/vol) acetonitrile/water/88\% formic acid.

The desalted tryptic peptides were analyzed by MALDITOF MS with alpha-cyano-4-hydroxycinnamic acid (CHCA) matrix (Fluka MS grade, Sigma-Aldrich, St. Louis). A 0.4- $\mu$ l portion of the peptide sample was applied to the MALDI target $(96 \times 2$, hydrophobic) and immediately was topped with an equal volume of CHCA solution $(10 \mathrm{mg} / \mathrm{ml}$ in $600: 370: 30$, $\mathrm{vol} / \mathrm{vol} / \mathrm{vol}$ ) acetonitrile/water/10\% trifluoroacetic acid). The sample and matrix mixture was allowed to cocrystallize and dry under ambient conditions. Spectra were acquired in the positive ion delayed extraction reflector mode on an Applied Biosystems (Foster City, CA, U.S.A.) Voyager DEPro MALDI-TOF MS employing a 20-Hz 337-nm nitrogen laser. Operating conditions were optimized to provide a resolution of 9,000 (full width at half height) at 2,000 Da. Spectra were calibrated using a six-peptide calibration standard mix and the close external standards calibration method. This provided a mass accuracy of 20 to $50 \mathrm{ppm}$.

Desalted digests were analyzed by nanospray quadrupole QqTOF MS on an Applied Biosystems/MDS Sciex QStar/Pulsar $i$ instrument fitted with a Proxeon (Odense, Denmark) nanospray source. A stable spray was achieved at $800 \mathrm{~V}$ in the presence of nitrogen curtain gas. Positive ion spectra were acquired in the profile MCA mode at a pulser frequency of $6.99 \mathrm{kHz}$. Collision-induced dissociation spectra (MS/MS) were acquired for peptides selected by the first quadrupole and were fragmented in the collision quadrupole at appropriate nitrogen collision gas pressures and collision energy settings.

Peak lists obtained from the MALDI-TOF mass spectra that had been deisotyped following baseline correction and noise reduction were queried against the soybean UniGene database, using a local copy of the MS Fit program of Protein Prospector (Clauser et al. 1999). For possible protein assignment, a minimum of four peptide matches, $150 \mathrm{ppm}$ mass tolerance, and a MOWSE score $>200$ were employed in the current study. The IntelliCal search function of Proteomics Solution 1 (Applied Biosystem, Foster City, CA, U.S.A.) was subsequently applied to the data. This program recalibrated the mass spectrum, using masses of the ions assigned from the most statistically significant match found in the first database search and then repeated the search, using a more stringent permissible mass tolerance of $15 \mathrm{ppm}$. IntelliCal searches were used to help confirm protein assignments from 150-ppm preliminary searches. Generally speaking, good candidates should be picked up by both the Protein Prospector and the IntelliCal. In other words, hits that were picked up by the Protein Prospector program but not by the IntelliCal program are usually suspicious, unless there is other evidence (such as MW and pI values) to suggest the opposite. 
Nanospray QqTOF tandem mass spectra (centroided) were either submitted online to the Mascot search engine or peak lists were entered into the Protein Prospector MS-Tag program for searching against various databases. Spectra were de novo sequenced when no significant matches were obtained by the searches, and tentative sequences were queried against NCBInr databases using the Blast program. A minimum of two matching partial peptide sequences was required for tentative identifications.

\section{ACKNOWLEDGMENTS}

The authors thank the Proteomics Center at the University of MissouriColumbia for gel electrophoresis and mass spectrometry service, and $\mathrm{N}$ M. Boukli (Department of Microbiology and Immunology, School of Medicine, Universidad Central del Caribe, Bayamon, Puerto Rico) for help with PDQuest and root-hair isolation. The project was funded by a joint University of Missouri-Monsanto grant to G. Stacey.

\section{LITERATURE CITED}

Allen, N. S., and Bennett, M. N. 1996. Electro-optical imaging of F-actin and endoplasmic reticulum in living and fixed plant cells. Scanning Microscopy Suppl. 10:177-187.

Ané, J.-M., Kiss, G. B., Riely, B. K., Penmetsa, R. V., Oldroyd, G. E. D., Ayax, C., Lévy, J., Debellé, F., Baek, J.-M., Kalo, P., Rosenberg, C., Roe, B. A., Long, S. R., Denarié, J., and Cook, D. R. 2004. Medicago truncatula DMI1 required for bacterial and fungal symbioses in legumes. Science 303:1364-1367.

Bauchrowitz, M. A., Barker, D. G., and Truchet, G. 1996. Lectin genes are expressed throughout root nodule development and during nitrogenfixation in the Rhizobium-Medicago symbiosis. Plant J. 9:31-43.

Bestel-Corre, G., Dumas-Gaudot, E., Poinsot, V., Dieu, M., Dierick, J. F., van Tuinen, D., Remacle, J., Gianinazzi-Pearson, V., and Gianinazzi, S. 2002. Proteome analysis and identification of symbiosis-related proteins from Medicago truncatula Gaertn. by two-dimensional electrophoresis and mass spectrometry. Electrophoresis 23:122-137.

Bestel-Corre, G., Dumas-Gaudot, E., and Gianinazzi, S. 2004. Proteomics as a tool to monitor plant-microbe endosymbioses in the rhizosphere. Mycorrhiza 14:1-10.

Bibilova, T., and Gilroy, S. 2003. Root hair development. J. Plant Growth Regul. 21:383-415.

Bohlool, B. B., and Schmidt, E. L. 1974. Lectins: A possible basis for specificity in the Rhizobium-legume root nodule symbiosis. Science 185:269-271.

Bradford, M. 1976. A rapid and sensitive method for the quantitation of microgram quantities of protein utilizing the principle of protein dye binding. Anal. Biochem. 72:248-254.

Broughton, W. J., and Dilworth, M. J. 1971. Control of leghaemoglobin synthesis in snake beans. Biochem. J. 125:1075-1080.

Bucher, M., Schroeer, B., Willmitzer, L., and Riesmeier, J. W. 1997. Two genes encoding extensin-like proteins are predominantly expressed in tomato root hair cells. Plant Mol. Biol. 35:497-508

Cardenas, L., Vidali, L., Domnguez, J., Prez, H., Snchez, F., Hepler, P. K., and Quinto, C. 1998. Rearrangement of actin microfilaments in plant root hairs responding to Rhizobium etli nodulation signals. Plant Physiol. 116:871-877.

Cardenas, L., Thomas-Oates, J. E., Nava, N., Lopez-Lara, I. M., Hepler, P. K., and Quinto, C. 2003. The role of nod factor substituents in actin cytoskeleton rearrangements in Phaseolus vulgaris. Mol. Plant-Microbe Interact. 16:326-334.

Clauser, K. R., Baker, P. R., and Burlingame, A. L. 1999. Role of accurate mass measurement $( \pm 10 \mathrm{ppm})$ in protein identification strategies employing MS or MS/MS and database searching. Anal. Chem. 71:28712882 .

Cohn,. J., Day, R. B., and Stacey, G. 1998. Legume nodule organogenesis. Trends Plant Sci. 3:105-110.

Cullimore, J. V., Ranjeva, R., and Bono, J.-J. 2001. Perception of lipo-chitooligosaccharidic Nod factors in legumes. Trends Plant Sci. 6:24-30.

Cook, D. R. 1999. Medicago truncatula-A model in the making! Curr. Opin. Plant Biol. 2:301-304.

Dantan-Gonzalez, E., Rosenstein, Y., Quinto, C., and Sanchez, F. 2001. Actin monoubiquitylation is induced in plants in response to pathogens and symbionts. Mol. Plant-Microbe Interact. 14:1267-1273.

den Hartog, M., Musgrave, A., and Munnik, T. 2001. Nod factor-induced phosphatidic acid and diacylglycerol pyrophosphate formation: A role for phospholipase $\mathrm{C}$ and $\mathrm{D}$ in root hair deformation. Plant J. 25:55-65.

De Ruijter, N. C. A., Bisseling, T., and Emons, A. M. C. 1999. Rhizobium Nod factors induce an increase in sub-apical fine bundles of actin filaments in Vicia sativa root hairs within minutes. Mol. Plant-Microbe Interact. 12:829-832.

Dhonukshe, P., Laxalt, A. M., Goedhart, J., Gadella. T. W. J., and Munnik, T. 2003. Phospolipase D activation correlates with microtubule reorganization in living plant cells. Plant Cell 15:2666-2679.

Díaz, C. L., Melchers, L. S., Hooykaas, P. J. J., Lugtenberg, B. J. J., and Kijne, J. W. 1989. Root lection as a determinant of host-plant specificity in the Rhizobium-legume symbiosis. Nature 338:579-581.

Estabrook, E. M., and Sengupta-Gopalan, C. 1991. Differential expression of phenylalanine ammonia-lyase and chalcone synthase during soybean nodule development. Plant Cell 3:299-308.

Ganapathy, A., Wan, X.-F., Wan, J., Thelen, J., Emerich, D. W., Stacey, G., and $\mathrm{Xu}, \mathrm{D}$. 2004. Statistical assessment for Mass-spec protein identification using peptide fingerprinting approach. Pages 3051-3054 in: Proceedings of the 26th Annual International Conference of the Institute of Electronics and Electrical Engineers-Engineering in Medicine and Biology Society, San Francisco.

Geurts, R., and Bisseling, T. 2002. Rhizobium Nod factor perception and signaling. Plant Cell 14:S239-S249.

Halverson, L. J., and Stacey, G. 1985. Host recognition in the Rhizobiumsoybean symbiosis: Evidence for the involvement of lectin in nodulation. Plant Physiol. 77:621-625.

Harrison, C. J., Mould, R. M., Leech, M. J., Johnson, S. A., Turner, L. Schreck, S. L., Baird, K. M., Jack, P. L., Rawsthorne, S., Hedley, C. L., and Wang, T. L. 2000. The rug3 locus of pea encodes plastidial phosphoglucomutase. Plant Physiol. 122:1187-1192.

Havlis, J., Thomas, H., Sebela, M., and Shevchenko, A. 2003. Fast-response proteomics by accelerated in-gel digestion of proteins. Anal. Chem. 75:1300-1306.

Heazlewood, J. L., and Millar, A. H. 2003. Integrated plant proteomicsPutting the green genomes to work. Funct. Plant Biol. 30:471-482.

Hirsch, A. M. 1999. Role of lectins (and rhizobial exopolysaccharides) in legume nodulation. Curr. Opin. Plant Biol. 2:320-326.

Hoa, L. T.-P., Nomura, M., Kajivara, H., Day, D. A., and Tajima, S. 2004. Proteomic analysis on symbiotic differentiation of mitochondria in soybean nodules. Plant Cell Physiol. 45:300-308.

Hurkman, M. A., and Tanaka, C. K. 1986. Solubilization of plant membrane proteins for analysis by two-dimensional gel electophoresis. Plant Physiol. 81:802-806.

Iturbe-Ormaetxe, I., Matamoros, M. A., Rubio, M. C., Dalton, D. A., and Becana, M. 2001. The antioxidants of legume nodule mitochondria Mol. Plant-Microbe Interact. 14:1189-1196.

Ketelaar, T., and Emons, A. M. C. 2001. The cytoskeleton in plant cell growth: Lessons from root hairs. New Phytol. 152:409-418.

Kersten, B., Bürkle, L., Kuhn, E. J., Giavalisco, P., Konthur, Z., Lueking, A., Walter, G., Eickhoff, H., and Schneider, U. 2002. Large-scale plant proteomics. Plant Mol. Biol. 48:133-141.

Kwon, K.-H., Kim, M., Kim, J. Y., Kim, K. W., Kim, S. I., Park, Y. M., and Yoo, J. S. 2003. Efficiency improvement of peptide identification for an organism without complete genome sequence, using expressed sequence tag database and tandem mass spectral data. Proteomics 3:2305-2309.

Legocki, R. P., and Verma, D. P. 1980. Identification of "nodule-specific" host proteins (nodulins) involved in the development of rhizobium-legume symbiosis. Cell 20:153-163.

Lepek, V. C., D’Antuono, A. L., Tomatis, P. E., Ugalde, J. E., Giambiagi, S., and Ugalde, R. A. 2002. Analysis of Mesorhizobium loti glycogen operon: Effect of phosphoglucomutase (pgm) and glycogen synthase (g/gA) null mutants on nodulation of Lotus tenuis. Mol. Plant-Microbe Interact. 15:368-375.

Lévy, J., Bres, C., Geurts, R., Chalhoub, B., Kulibova, O., Duc, G., Journet, E.-P., Ané, J.-M., Lauber, E., Bisseling, T., Dénarié, J., Rosenberg, C., and Debellé, F. 2004. A putative $\mathrm{Ca}^{2+}$ and calmodulin-dependent protein kinase required for bacterial and fungal symbioses. Science 303:1361-1364.

Lhuissier, F. G. P., De Ruijter, N. C. A., Sieberer, B. J., Esseling, J. J., and Emons, A. M. C. 2001. Time course of cell biological events evoked in legume root hairs by Rhizobium Nod factors: State of the art. Ann. Bot. 87:289-302.

Loh, J., and Stacey, G. 2001. Feedback regulation of the Bradyrhizobium japonicum nodulation genes. Mol. Microbiol. 41:1357-1364.

Lum, M. R., and Hirsch, A. M. 2003. Roots and their symbiotic microbes: Strategies to obtain nitrogen and phosphorus in a nutrient-limiting environment. J. Plant Growth Regul. 21:368-382.

Matamoros, M. A., Dalton, D. A., Ramos, J., Clemete, M. R., Rubio, M. C., and Becana, M. 2003. Biochemistry and molecular biology of antioxidants in the rhizobia-legume symbiosis. Plant Physiol. 133:499-509. 
Mathesius, U., Imin, N., Chen, H., Djordjevic, M. A., Weinman, J. J. Natera, S. H. A., Morris, A. C., Kerim, T., Paul, S., Menzel, C., Weiller, G. F., and Rolfe, B. G. 2002. Evaluation of proteome reference maps for cross-species identification of proteins by peptide mass fingerprinting. Proteomics 2:1288-1303.

Mathesius, U., Keijzers, G., Natera, S. H. A., Weinman, J. J., Djordjevic, M. A., and Rolfe, B. G. 2001. Establishment of a root proteome reference map for the model legume Medicago truncatula using the expressed sequence tag database for peptide mass fingerprinting. Proteomics 1:1424-1440.

Miller, D., de Ruijter, N., and Emons, A. 1997. From signal to form: Aspects of the cytoskeleton-plasma membrane-cell wall continuum in root hair tips. J. Exp. Bot. 48:1881-1896.

Mitra, R. M., and Long, S. R. 2004. Plant and bacterial symbiotic mutants define three transcriptionally distinct stages in the development of the Medicago truncatula/Sinorhizobium meliloti symbiosis. Plant Physiol. 134:595-604.

Mooney, B. P., and Thelen, J. J. 2004. High-throughput peptide mass finger printing of soybean seed proteins: Automated workflow and utility of UniGene expressed sequence tag databases for protein identification. Phytochemistry 65:1733-1744.

Morris, A. C., and Djordjevic M. A. 2001. Proteome analysis of cultivarspecific interactions between Rhizobium leguminosarum biovar trifolit and subterranean clover cultivar Woogenellup. Electrophoresis 22:586598.

Natera, S. H., Guerreiro, N., and Djordjevic, M. A. 2000. Proteome analysis of differentially displayed proteins as a tool for the investigation of symbiosis. Mol. Plant-Microbe Interact. 13:995-1009.

Oldroyd, G. E. D. 2001. Dissecting symbiosis: Developments in Nod factor signal transduction. Ann. Bot. 87:709-718.

Panter, S., Thomson, R., de Bruxelles, G., Laver, D., Trevaskis, B., and Udvardi, M. 2000. Identification with proteomics of novel proteins associated with the peribacteroid membrane of soybean root nodules. Mol. Plant-Microbe Interact. 13:325-333.

Porta, H., and Rocha-Sosa, M. 2002. Plant lipoxygenases. Physiological and molecular features. Plant Physiol. 130:15-21.

Rolfe, B. G., Mathesius, U., Djordjevic, M., Weinman, J., Hocart, C., Weiller, G., and Bauer, W. D. 2003. Proteomic analysis of legumemicrobe interactions. Comp. Funct. Genom. 4:225-228.

Rosendahl, L., Vance, C. P., and Pedersen, W. B. 1990. Products of dark $\mathrm{CO}_{2}$ fixation in pea root nodules support bacteroid metabolism. Plant Physiol. 93:12-19.

Rossignol, M. 2001. Analysis of the plant proteome. Curr. Opin. Biotech. 12:131-134.

Saalbach, G., Erik, P., and Wienkoop, S. 2002. Characterisation by proteomics of peribacteroid space and peribacteroid membrane prepara- tions from pea (Pisum sativum) symbiosomes. Proteomics 2:325-337.

Schultze, M., and Kondorosi, A. 1998. Regulation of symbiotic root nodule development. Annu. Rev. Genet. 32:33-57.

So, J.-S., Hodgson, A. L. M., Haugland, R., Leavitt, M., Banfalvi, Z., Nieuwkoop, A. J., and Stacey, G. 1987. Transposon-induced symbiotic mutants of Bradyrhizobium japonicum: Isolation of two gene regions essential for nodulation. Mol. Gen. Genet. 207:15-23.

Stougaard, J. 2000. Regulators and regulation of legume root nodule development. Plant Physiol. 124:531-540.

Streeter, J. G. 1995. Recent developments in carbon transport and metabolism in symbiotic systems. Symbiosis 19:175-196.

Thiellement, H., Bahrman, N., Damerval, C., Plomion, C., Rossignol, M., Santoni, V., de Vienne, D., and Zivy, M. 1999. Proteomics for genetic and physiological studies in plants. Electrophoresis 20:20132026.

Trevaskis, B., Colebatch, G., Desbrosses, G., Wanrey, M., Wienkoop, S., Saalbach, G., and Udvardi, M. 2002. Differentiation of plant cells during symbiotic nitrogen fixation. Comp. Funct. Genomics 3:151-157.

van Rhijn, P., Goldberg, R. B., and Hirsch, A. M. 1998. Lotus corniculatus nodulation specificity is changed by the presence of a soybean lectin gene. Plant Cell 10:1233-1250.

van Wijk, K. 2001. Challenges and prospects of plant proteomics. Plant Physiol. 126:501-508.

Watson, B. S., Asirvatham, V. S., Wang, L., and Sumner, L. W. 2003. Mapping the proteome of barrel medic (Medicago truncatula). Plant Physiol. 131:1104-1123.

Westbrook, J. A., Yan, J. X., Wait, R., Welson, S. Y., and Dunn, M. J. 2001 Zooming-in on the proteome: Very narrow-range immobilized $\mathrm{pH}$ gradients reveal more protein species and isoforms. Electrophoresis 22:2865-2871.

Wienkoop, S., and Saalbach, G. 2003. Proteome analysis. Novel proteins identified at the peribacteroid membrane from Lotus japonicus root nodules. Plant Physiol. 131:1080-1090.

Young, N. D., Mudge, J., and Ellis, T. H. N. 2003. Legume genomes: More than peas in a pod. Curr. Opin. Plant Biol. 6:199-204.

\section{AUTHOR-RECOMMENDED INTERNET RESOURCES}

The Soybean EST Project database: 129.186.26.94/soybeanest.html National Center for Biotechnology Information, //www.ncbi.nlm.nih.gov University of California San Francisco Mass Spectrometry Facility Protein Prospector: http://prospector.ucsf.edu

Mascot search engine: www.matrixscience.com)

National Center for Biotechnology Information Blast website: www.ncbi.nlm.nih.gov/BLAST 